\title{
Os códigos de Oyá - elementos simbólicos da Dança de lansã no Afoxé Oju Omim Omorewá
}

The codes of Oyá-symbolic elements from the Dance of lansã as performed by Afoxé Oju Omin Omorewá

Daniela Beny Polito Moraes ${ }^{1}$

Teodora de Araújo Alves ${ }^{2}$ 


\section{Resumo}

Este artigo traz os elementos simbólicos da Dança de lansã usados como base na criação coreográfica do espetáculo "Chão Batido - terra de negros e mestiços" do Afoxé Oju Omim Omorewá. Apresentamos como a mitologia iorubá e a comunicação oral compõem a criação coreográfica do afoxé e apontam para o entendimento da dança nas religiões de matrizes africanas, sob a perspectiva da Antropologia da Performance, com bases em Richard Schechner e Zeca Ligiéro. Visamos aqui estabelecer diálogo entre os fundamentos da Antropologia da Performance e nossas interlocutoras - as lalorixás Nany Moreno e Isabel Caetano - delimitando o espaço da performance artística como objeto/sujeito de estudo.

Palavras-chave: Orixá; lansã; Afoxé; dança; antropologia da performance.

\section{Abstract}

This article summons the symbolic elements of the Dance of lansã that are used as basis to create the choreography of the show "Chão Batido - terra de negros e mestiços", by the Afoxé Oju Omim Omorewá. We show how the Yoruba mythology and the principle of oral communication comprise the choreographic creation of the afoxé and point to the understanding of dance in the religions of African origin. We do so from the perspective of an Anthropology of Performance, drawing on Richard Schechner and Zeca Ligiéro. In this paper, we aim to establish a dialogue between the foundations of Anthropology of Performance and our interlocutors - the Ialorixás Nany Moreno and Isabel Caetano - delimiting the space of artistic performance as object/subject of investigation..

Keywords: Orisha; lansã; Afoxé; dance; anthropology of performance.
ISSN: 1414.5731

E-ISSN: 2358.6958
${ }^{1}$ Mestranda em Artes Cênicas na Universidade Federal do Rio Grande do Norte. Bolsista CAPES. Associada da Patacuri - Cultura, formação e comunicação Afro-ameríndio.daniela.beny@gmail.com

${ }^{2}$ Docente Associada no Departamento de Artes da Universidade Federal do Rio Grande do Norte, atuando no Curso de Licenciatura em Dança. Atua no Programa de Pós-Graduação em Artes Cênicas da Universidade Federal do Rio Grande do Norte (UFRN). teodora.alves@gmail.com 


\section{Os códigos de Oyáz - elementos simbólicos da Dança de lansã no Afoxé Oju Omim Omorewát}

No conceito geral, compreende-se que os afoxés são manifestações religiosas dos terreiros de Candomblé 5 em espaço público - também conhecidos como Candomblé de Rua - com elementos sagrados trazidos para o ambiente profano. Porém, tal designação não se aplica à configuração do Afoxé Oju Omim Omorewá que, mesmo coordenado por duas lalorixás ${ }^{6}$ - Mãe Nany Moreno e Mãe Isabel Caetano - , possui mais apelo artístico que religioso, onde inicialmente se considerava um grupo percussivo, mas, com o passar do tempo, veio agregando outros elementos como: dança, poesia e teatro na composição de suas apresentações. Se, em sua fundação, em 2000, ele produzia shows, hoje em dia, se considera produzindo espetáculos.

Situado na cidade de Maceió, no estado de Alagoas, no populoso bairro do Jacintinho, o Afoxé desenvolve atividades artísticas, culturais e sociais voltadas para jovens do entorno; porém, por falta de espaço físico adequado, alguns ensaios dos espetáculos do Afoxé foram realizados no centro Cultura Afro e Religiosa Ilé Nifé Omí Omo Posú Bétá, espaço religioso e de atividades culturais sob direção da lalorixá Miriam - Mãe Miriam, no bairro da Ponta da Terra, assim como ensaios na sede do grupo Coletivo Afro-Caeté, grupo que visa resgatar a arte periférica através de atividades como oficinas, apresentações e a criação de um maracatu, no bairro do Jaraguá. No caso específico do espetáculo "Chão Batido - terra de negros e mestiços", os ensaios foram realizados entre os meses de março e agosto de 2014, com estreia em 13 de agosto de 2014, no Teatro Deodoro, em Maceió (AL).

O acompanhamento dos ensaios se deu por conta da escrita da monografia, de nossa autoria, intitulada "A codificação corporal da Dança de lansã nas coreografias do Afoxé Oju Omim Omorewá", para conclusão do curso de Especialização em Antropologia pela Universidade Federal de Alagoas, por Daniela Beny Polito Moraes, e atualmente vem sendo aprofundada na nossa pesquisa de mestrado. A Dança de lansã como possibilidade de treinamento do performer", no Programa de Pós-Graduação em Artes Cênicas da Universidade Federal do Rio Grande do Norte, sob orientação da professora doutora Teodora de Araújo Alves.

Outro aspecto particular a ser observado nas práticas do Afoxé é que, mesmo tendo como coordenadoras lalorixás e levando para cena elementos fortemente relacionados aos rituais religiosos, o grupo é composto por iniciados e não-iniciados nas religiões de matrizes africanas.

\footnotetext{
${ }^{3}$ Também conhecida como lansã, deusa lorubá, cultuada inicialmente às margens do rio Niger. Está relacionada com o elemento fogo no Candomblé e com o despacho dos eguns (espíritos dos mortos) na Umbanda, encaminhando os mortos para o outro mundo. Quando associada ao Orixá Xangô, está relacionada com os relâmpagos, trovões e tempestades. No sincretismo religioso, é representada por Santa Bárbara. "Yansã", em Nagô, também significa "Mãe do céu rosado" ou "Mãe do entardecer". Dirige os ventos, as tempestades e a
}

sensualidade feminina

4Tradução: Olhos d'água dos Filhos da Beleza.

5 Segundo Beatriz Góis Dantas (1988), o termo Candomblé é "usualmente empregado na Bahia para designar a religião afro-brasileira no seu conjunto, mas também o local do culto e das festas religiosas" (Dantas, 1988, p. 258).

6 Literalmente significa "Mãe que cuida do Orixá", o termo serve para designar a função das Sacerdotisas do Candomblé. 


\section{Dançar-contar-cantar}

A corporeidade, quando pensada na perspectiva das comunidades de terreiro de origem iorubá, possui como característica o corpo como um microcosmos capaz de trazer em si informações de origem ancestral, explicando assim mitos e arquétipos apresentados durante a roda do Xirê7.

Porém, podemos aprofundar nossas reflexões sobre as várias vertentes de entendimento do termo corporeidade dentro da perspectiva da Sociologia, da Filosofia, da Dança e da Antropologia.

O filósofo Merleau-Ponty, em sua abordagem fenomenológica de compreensão do ser humano inserido corporalmente no mundo, agindo e reagindo ao contato com outros seres humanos, nos aponta que

O corpo é nosso meio geral de ter um mundo. Ora ele se limita aos gestos necessários à conservação da vida e, correlativamente, põe em torno de nós um mundo biológico; ora, brincando com seus primeiros gestos e passando de seu sentido próprio a um sentido figurado, ele manifesta através deles um novo núcleo de significação: é o caso dos hábitos motores da dança. Ora, enfim a significação visada não pode ser alcançada pelos meios naturais do corpo; é preciso então que ele construa um instrumento, e ele projeta em torno de si um mundo cultural (Merleau-Ponty, 1999, p. 203).

O sociólogo Pierre Bourdieu nos traz a reflexão de como a corporeidade é construída como expressão do ser-no-mundo, sendo registrada, codificada e transmitida geração após geração, considerando tanto aspectos genéticos quanto aspectos sociais, reforçando o entendimento de corporeidade apontado por Merleau-Ponty. Segundo Teodora de Araújo Alves, professora do PPGARC-UFRN:

[...] esse processo de registrar e renovar nos corpos tudo que nós e nossos antepassados vivemos, Pierre Bourdieu denomina de habitus ${ }^{8}$ [...]. Nesse sentido Bourdieu acredita que há uma motivação incorporada que permite a realização de algumas ações recorrentes. E essa ação ocorre por meio do diálogo entre a história feita corpo e a história feita coisa (Alves, 2006, p. 52).

\section{Para a dançarina e pesquisadora Suzana Martins:}

O termo corporeidade refere-se ao tratamento dado ao corpo como um conjunto de elementos simbólicos estruturados para um determinado fim. No Candomblé, a corporeidade é construída a partir da união espiritual decorrente da intervenção primordial da divindade. [...] Nesse contexto, a corporeidade é representada pelo corpo em movimento - o jeito de dançar - que ostenta vestimenta litúrgica, atributos e adereços simbólicos embalados pela qualidade específica da música e do Orixá (Martins, 2008. p. 81).

Em paralelo, mesmo havendo divergências num aspecto mais amplo dos con-

\footnotetext{
7 "[...] a designação geral usada para nominar a sequência das danças rituais dos Candomblés [...] Segue-se uma ordem pré-estabelecida, como se fosse um roteiro teatral, reunindo Orixás afins (Lody, Sabino, 2011, p. 103)".
}

8 "Essa história incorporada e resgatada constitui a História feita coisa, a qual é levada, atualizada, reativada pela história feita corpo e que não só atua como traz de volta aquilo que leva (Bourdieu, 2011, p. 83)". 
ceitos e significados das culturas afro-brasileiras sobre os usos do corpo em relação ao pensamento "mais ocidental", por assim dizer, percebemos uma zona de diálogo com um contexto completamente diferente, quando Csordas (2008) - dentro dos encontros carismáticos da Igreja Católica nos Estados Unidos, coloca que

Se a corporeidade realmente nos ajuda a compreender uma prática particular, ela deveria também nos ajudar a compreender como as práticas se relacionam entre si [...] A combinação de usos ativos e passivos do corpo em uma prática parece ser o operador concreto que permite a comunhão experiencial do humano e o divino em um corpo falante (Csordas, 2008, p. 132).

O que percebemos aqui é a convergência das mais diversas vertentes de pensamento dos usos do corpo, seja no contexto cotidiano, seja no religioso ou artístico, apontando o corpo como meio de transmissão de informações ancestrais, conscientes ou inconscientes.

Contudo, por mais que a tradição iorubá seja pautada na transmissão oral de conhecimento, o Orixá em terra - no momento do transe mediúnico - se comunica por meio de uma linguagem não-verbal, a dança. A codificação das coreografias será capaz de, junto ao acompanhamento musical, transmitir a trajetória mitológica de cada Orixá, sendo possível, através de seus gestos, perceber quais as ferramentas de trabalho que manipulam, quais elementos da natureza estão relacionados e, inclusive, qual o temperamento manifesto em seu arquétipo e as interações com os outros Orixás.

Ligiéro (2011, p. 134) faz referência ao filósofo do Congo, Busenki K. Kia Fu -Kiau, ao citar que nas culturas de origem africana a expressão cantar-dançar-batucar se aplica aos elementos performativos das expressões artístico-culturais e religiosas, que não dissociam os vários usos do corpo. Então, é possível considerar que esse corpo canta-dança-batuca liga o mundo dos humanos ao mundo espiritual e transmite histórias/mitos com distintos caráteres performáticos, seja como ritual ou prática artística.

Por performance, recorremos aqui ao conceito de Schechner (2013) ao apontar que

[...] uma definição de performance pode ser: comportamento ritualizado condicionado/permeado pelo jogo. Rituais são de uma forma de as pessoas lembrarem. Rituais são memórias em ação, codificadas em ações. [...]. O jogo dá às pessoas a chance de experimentarem temporariamente o tabu, o excessivo e o arriscado (Schechner, p. 49 e 50).

Por uma questão de tradução e das características da língua portuguesa, perdemos as possibilidades de interpretação do termo jogo, onde aqui nos pautaremos na abrangência de significados do verbo to play, em inglês, que pode ser traduzido como tocar, jogar, atuar. Há aqui um ponto de encontro sobre o caráter performático vinculado a uma fronteira entre o cultural e o artístico. 
O ritual e o jogo (play) se encontram em vários significados e usos para o mesmo termo. Logo, o corpo que performa jogando/tocando/atuando o faz quando cantadança-batuca.

Ao seguir na relação direta entre jogo (play) e ritual, chegamos à palavra Xirê - a qual já nos referimos anteriormente - que, além de designar a sequência das danças rituais do Candomblé (Lody, Sabino, 2011, p. 103), também pode ser traduzida do iorubá como jogo, movimento lúdico, divertimento, então teríamos um corpo que joga/toca/atua cantando-dançando-batucando em divertimento, brincando. Indo de performer a player no sentido mais abrangente da palavra. E nem assim, no limite entre o sagrado e o profano, deixa de ser um meio de estabelecer contato entre humanos e divindades nem de contar seus mitos e histórias.

\begin{tabular}{|c|c|c|}
\hline Schechner (antropólogo) & Bunseki Fu-Kiau (filósofo) & Lody (antropólogo) \\
\hline To play & Xirê \\
(tocar, jogar, atuar) & Cantar-dançar-batucar & $\begin{array}{c}\text { (jogo, divertimento, mo- } \\
\text { mento lúdico) }\end{array}$ \\
\hline
\end{tabular}

Quadro 01: Relação do jogo sobre diferentes pontos de vista relacionados à performance afro-brasileira

\section{lansã - do búfalo à tempestade}

Depois de observarmos os possíveis conceitos de corporeidade em diversas vertentes e dentro da cultura iorubá, se faz necessário entender o arquétipo de lansã. Essa divindade feminina da cultura iorubá está relacionada com os elementos fogo e ar, e com o trânsito dos eguns (espíritos dos mortos) para o plano espiritual, dirige os ventos e as tempestades. Segundo a professora Denise Zenicola (2014), "Representa o poder enérgico da não submissão, da impetuosidade, [...] da conquista libertária, da impossibilidade de aprisionamento, tal qual seu elemento, o vento (Zenicola, 2014, p. 41)".

Além dessas características, várias lendas apresentam Oyá/lansã como sendo uma mulher de ações expansivas, muito curiosa e com constantes trocas de parceiros amorosos, o que faz com que de cada relacionamento ela aprendesse um pouco dos segredos e da manipulação dos elementos da natureza correspondentes aos seus amantes.

Dentre um universo de lendas e de cantigas sagradas, muitas lendas contam/ cantam os feitos de lansã, desde histórias nas quais ela se transforma em búfalo para proteger seus filhos - sendo ela a única lyabá9 que se transforma em animal - ou em vento para se libertar do cárcere, além de canções que se referem à lansã como uma borboleta.

Pensando no arquétipo de lansã, é necessário levar em conta que, para a cultura iorubá, o Orixá é considerado a personificação das forças da natureza. Sendo assim, a dança de lansã trará em sua corporeidade aspectos referentes à personifica

9 Designação feminina de Orixá. 
ção do búfalo, do vento e da borboleta, pensando também que existem variedades quanto a essas representações. Sendo o vento, sua dança pode trazer movimentos que variariam de uma leve brisa até uma forte tempestade. Além disso, ainda existem as características do comportamento humano desta deidade, que mescla força e sensualidade, agilidade e peso.

lansã está muito relacionada à guerra e isso se evidencia nos seus paramentos, que, no seu caso, são armas e ferramentas de trabalho para desenvolvimento de suas funções no campo espiritual. Tanto em representações pictóricas quanto nas Saída de Orixá 10 , ela normalmente porta na mão esquerda o eruexim- uma espécie de espanador feito de crina de cavalo usado simbolicamente para espanar os eguns, mas também fazendo referência ao movimento da cauda do búfalo para afugentar as moscas - e na mão direita uma espada ou um chicote.

Ao correlacionar todas essas particularidades do arquétipo de lansã, é possível então elencar as características de sua dança. Segundo a professora doutora Nadir Nóbrega em entrevista (informação verbal):

[...] vem aqueles movimentos rápidos, não são movimentos sinuosos, o movimento de Iansã eles são rápidos, eles são de dentro pra fora... [...] a cintura onde ela joga a perna para um lado, o quadril ele se movimenta do lado oposto, então tem a questão da polirritmia [...] e da polirritmia onde o braço dela, ela tá fazendo movimentos circulares e ao mesmo tempo ela tá afastando os eguns e a cintura com o quadril dela tá fazendo a sinuosidade e os pés estão indo noutro andamento [...] numa dança de Iansã mais conhecida você não tem um centro. A Dança de Iansã geralmente está no nível alto (Nóbrega, 2014).

Pensando nos aspectos arquetípicos de lansã, apontados durante o levantamento de material e nas características de movimento, propomos a tabela abaixo para relacionar essas características e elementos significantes, além da melhor visualização da variedade de ações executadas. A intenção aqui é proporcionar um melhor entendimento de como as coreografias se estruturam, observando que nos movimentos codificados de sua dança estarão presentes os animais aos quais lansã está relacionada, a força da natureza onde/como se manifesta e os verbos que designam suas atividades no plano espiritual. Na tabela abaixo, consideramos como Qualidade de Movimento o que tem mais destaque na execução da dança, associando à "característica" principal descrita através da palavra que expressa o movimento, sendo os outros itens autoexplicativos.

\begin{tabular}{|c|c|c|}
\hline QUALIDADE DO MOVIMENTO & Velocidade & Força \\
\hline CARACTERÍSTICA & Leveza & Peso \\
\hline ANIMAL ASSOCIADO & Borboleta & Bufalo \\
\hline $\begin{array}{c}\text { FORÇA DA NATUREZA } \\
\text { REPRESENTADA }\end{array}$ & Brisa & Tempestade \\
\hline VERBO & Espanar & Cortar \\
\hline
\end{tabular}

Quadro 02 - Códigos corporais presentes na Dança de lansã

10 Cerimônia de iniciação de filho(a)s-de-santo - também conhecido por laô à comunidade. no Candomblé, é quando o laô será apresentado ao público numa festa aberta 
Abrimos aqui um breve diálogo com outra colocação de Zenicola (2014, p. 110), quando a mesma também propõe um quadro que sugere uma síntese das ações da dança de lansã.

\begin{tabular}{|c|c|c|c|c|c|c|}
\hline AÇÃO & $\begin{array}{c}\text { AÇÃO } \\
\text { BÁSICA }\end{array}$ & $\begin{array}{c}\text { AÇ̃̃O } \\
\text { SECUNDÁRIA }\end{array}$ & PESO & TEMPO & ESPAÇO & FLUÊNCIA \\
\hline Talhar & $\begin{array}{c}\text { Forte } \\
\text { Flexível } \\
\text { Expandida } \\
\text { e/ou } \\
\text { recolhida }\end{array}$ & $\begin{array}{c}\text { Bater } \\
\text { Ativar } \\
\text { Chicotear }\end{array}$ & $\begin{array}{c}\text { Firme } \\
\text { ou suave } \\
\text { Enérgica }\end{array}$ & $\begin{array}{c}\text { Súbita } \\
\text { Curta } \\
\text { duração }\end{array}$ & $\begin{array}{c}\text { Direta } \\
\text { Imediata } \\
\text { Flexível } \\
\text { elinear }\end{array}$ & Livre \\
\hline
\end{tabular}

Quadro 3 - Características da Dança de lansã segundo Denise Mancebo Zenicola

Mesmo que os aspectos apontados não sejam os mesmos, é possível traçar um paralelo nas observações feitas nos dois quadros se relacionarmos, por exemplo, Verbo (quadro 2) com Ação Secundária (quadro 3), além de outros elementos que, embora trazidos de maneira subjetiva e com nomenclaturas diferentes, é possível interpretar de modos parecidos, como Característica (quadro 2) e Peso (quadro 3).

Com base em todos esses apontamentos, foi possivel observar e rever as filmagens dos ensaios do Afoxé e perceber os elementos indicados pelas mais diversas fontes, mesmo que num ensaio o estado de concentração das dançarinas não seja o mesmo de uma apresentação, o que, consequentemente, altera a qualidade de energia e dos movimentos da dança. O mais pontual nestas observações posteriores foram aspectos relacionados à polirritmia da dança, aos movimentos circulares dos braços e à comunicação da performer/player em movimentos executados de dentro para fora, partindo do centro para as extremidades, sugerindo a característica expansiva de lansã.

É importante salientar que, mesmo sendo executados por dançarinas iniciadas no Candomblé - no caso específico das que dançavam em reverência à lansã neste espetáculo -, os movimentos apresentavam diferenças perceptíveis quanto às qualidades apontadas nas tabelas acima e em relação ao estado de transe durante o Xirê, ocorrendo, assim, a mimese do movimento do Orixá em terra.

\section{Composições coreográficas}

Em entrevista, a lalorixá Nany Moreno discorreu um pouco sobre o processo de criação do espetáculo Chão Batido - terra de negros e mestiços. Segundo ela:

A gente vai falar sobre um Brasil mestiço, essa mistura de povo, a gente apesar de ser muito misturado se olha de um jeito muito desigual, muito preconceituoso um para outro, inclusive de um negro para o outro. Tem essa história de que um negro não olha no olho de outro negro porque tem vergonha de se ver, de perceber a própria imagem, e é esse preconceito que a gente quer combater. O show vai ser a chegada do navio negreiro, com as mulheres, com figurinos mais rústicos, sem luxo, porque os negros escravizados não trouxeram luxo. Agora teremos uma das meninas do grupo interpretando um trecho do texto 'Navio Negreiro' de Castro Alves. Para esse espetáculo pesquisamos também a Santeria Cubana, danças de tribos africanas, toque do Ilê com jongo e pra finalizar um grande samba de roda (Moreno, 2014). 
Além da coordenação, Mãe Nany também assina a direção, roteiro, coreografias e algumas composições do espetáculo. Como método de criação, ela relatou que opta por dois processos. As coreografias para execução em conjunto são criadas por ela, que, seguindo o que foi estabelecido em seu roteiro, correlaciona elementos de acordo com o que está sendo composto como trilha sonora. Nos solos, geralmente aponta uma base e as dançarinas desenvolvem suas coreografias de acordo com seu repertório corporal.

Estes solos geralmente são reverências feitas aos Orixás, com o toque percussivo associado à entidade homenageada e com canções onde as letras trazem referências a sua mitologia. Especificamente no solo para lansã, três dançarinas foram "avaliadas" para a escolha de quem apresentaria o número. A base coreográfica se mantinha, mas algumas características acabavam sendo potencializadas de dançarina para dançarina, por exemplo: enquanto uma apresentava mais velocidade nos movimentos - o que é característica de lansã ao ser relacionada aos ventos -, outra já trazia na sua codificação corporal elementos mais associados à força física - o que aproximaria sua corporeidade ao elemento do búfalo.

Para compreensão da liberdade de criação das dançarinas do Afoxé, levemos em consideração que a relação do corpo dentro da cultura africana nos propõe a não dissociação das ações de tocar-cantar-dançar, mas cada parte do corpo é designada como um centro energético. Nas coreografias cada uma delas estabelecerá uma relação diferente entre o praticante da dança - sob a perspectiva religiosa ou não - e o ambiente que o circunda, como o apontado por Ligiéro (2011). Na publicação “Dança afro - sincretismo de movimentos", a professora Nadir Nóbrega exemplifica:

Podemos afirmar que a força dos movimentos da Dança Afro é transmitida por três canais energéticos [...]. CABEÇA: Parte superior do corpo que raciocina, que ordena a ação do resto do corpo. Ponto referencial da natureza: o céu. TRONCO: Parte média do corpo. Elemento importante na procriação e sedução, ajuda a requebrar no andar e no dançar. Ponto referencial da natureza: o mar. Podemos estabelecer uma relação com as estórias dos Orixás Oxum e Iemanjá, as rainhas da procriação, sedução, beleza e fertilidade. PÉS: Parte inferior do corpo. Elementos que locomovem o indivíduo para a guerra, o trabalho e a festa. São eles que transportam sensações para todo o corpo através dos solados (Nóbrega, 1992, p. 17).

Ainda complementa sobre os princípios básicos da dança Afro, que são:

Pés paralelos e descalços (quando fora do chão ficam dobrados), coluna ereta (sem rigidez) inclinada para a frente ou lados, quadris relaxados para trás, movimentos requebrados, soltos e independentes, ritmo variado, rico, percutido em contratempo com os pés no chão e pouquíssimas mudanças de nível (Nóbrega, 1992, p. 20).

Concluímos que os usos do corpo são múltiplos e expressivos, tanto para as práticas cotidianas como extracotidianas. Segundo Barba (2012, p. 16): "[as] técnicas cotidianas do corpo são geralmente caracterizadas pelo princípio do menor esforço: ou seja, obter o máximo de resultado com o menor uso de energia [...], visam à comunicação" e de acordo com sua abordagem, "[as] técnicas extracotidianas [...] estão 
baseadas no desperdício de energia [...] o princípio do uso máximo de energia para obter um resultado mínimo [...] visam à informação".

Então, a comunicação e informação são características fundamentais nesse processo de performance que envolve os próprios Orixás, tanto no contexto religioso quanto no artístico.

Complementando Nóbrega (1992), Falcão (2002) nos situa quanto aos possíveis usos deste corpo dançante que comunica os aspectos dos médiuns, dos dançarinos e dos Orixás em terra:

Há significados e funções que se definem por regiões, partes do corpo. O torso é o centro expressivo da dança, com a respiração, de onde os movimentos dependem para garantir sua força, versatilidade e tensão. Os braços e as pernas produzem o vocabulário dos gestos. As articulações permitem uma variedade de movimentos, elasticidade, força e beleza. A cabeça gira, inclina, direciona a força do movimento, o foco. A coluna vertebral nos dá a noção do eixo corporal: é responsável pela condição estática e dinâmica reunindo as outras partes do corpo (Falcão, 2002, p. 83).

Sendo assim, a criação e/ou modificação de uma partitura corporal - ou vocabulário de gestos - é uma das partes do processo de composição de uma obra artística que tem como forma de comunicação o corpo e seus códigos, como nos propõe Schechner ao afirmar que:

Uma partitura corporal pode ser mudada porque não é um 'evento natural', mas um modelo de escolha humana individual e coletiva. Uma partitura existe, como diz o antropólogo norte-americano Victor Turner, 'no subjuntivo', no que Stanislavski chamava de 'como se' (Schechner, 2013, p. 245).

Convêm salientar que Mãe Nany, para evitar qualquer contratempo, como o risco das dançarinas entrarem em transe durante uma apresentação, já que em cena haverá elementos propícios a isso, opta que as dançarinas não representem seus próprios Orixás em cena, exceto as que são ekedes ${ }^{11}$, que pela própria atribuição de seu cargo não entram em transe. Além da segurança das dançarinas, evitar o transe no momento do espetáculo é uma preocupação em relação à leitura a ser feita pelo público. Segundo Nany (informação verbal) - que também é filha de lansã:

Uma coisa é eu montar uma coreografia pra o meu Orixá, que chegue bem perto dele. Outra coisa é eu dançar Iansã, vestida de Iansã, as pessoas não vão assimilar uma coisa a outra, as pessoas vão dizer: A Nany tá de Iansã no palco fazendo isso e isso. Então eu tenho cuidado (Moreno, 2014)

Assim, esse dado revela a preocupação em manter fronteiras no tênue limite entre a performance religiosa e a performance artística na Dança de lansã. Há uma sincronicidade vivenciada na performance artística que é sobre prática religiosa. Atra- 
vés desse dado etnográfico registrado (evitação do transe), há uma clara intenção de se evitar que haja uma mesma atuação entre os dois papéis sociais desempenhados por Nany: o de lalorixá e o de dançarina.

\section{Conclusão}

Percebemos que a dança dentro da cultura afro-brasileira integra elementos físicos, psíquicos, intelectuais e emocionais de um determinado grupo social, reforçando para aquela comunidade - neste caso o Afoxé, mas também aplicável às comunidades de terreiros - o corpo como propulsor e símbolo de poder e de disciplina, coesão e identidade. Além do caráter litúrgico do Candomblé (Falcão, 2002), a Dança de lansã propicia às dançarinas participantes do Afoxé a condição de empoderamento feminino, étnico e religioso, uma vez que as coreografias trazem em si elementos mitológicos e arquetípicos de uma divindade feminina permeada por lendas que evidenciam a figura da mulher num lugar de protagonismo e independência nas suas escolhas, como nos propõe Alves (2006) ao apontar as perspectivas e possibilidades de construção e desvelar através do corpo:

Há significados e intencionalidades na expressão verbal e não verbal de cada corpo e de muitos corpos que se constroem na interação com o mundo. Corpos que dizem e ouvem, que criam e recriam, que aprendem e ensinam ao longo de suas histórias de vida. Fazem-se verdadeiros em seus rituais, em suas celebrações, em suas atitudes. Formulam seus conceitos, suas concepções, seus conhecimentos [...] Pela via da corporeidade, através da expressão do ser no mundo, e, sendo esta expressão uma dança afro-brasileira, entendemos que há uma enunciação de sentidos e significados próprios da etnicidade do sujeito, de sua cultura, de sua sociedade de origem (Alves, 2006, p. 61).

Durante a realização desta pesquisa, percebemos que, diferente de outras danças codificadas de origem europeia, a Dança de Orixá permite a participação de todos os corpos, com suas mais variadas características de peso, qualidade de movimento e vocabulários de gestos preexistentes. Mesmo havendo uma base coreográfica, nos solos cada dançarina possuía a liberdade de criação, valorizando, assim, a experiência, inclusive de dançarinas que não tiveram sua formação dentro de escolas de dança - como a própria Mãe Nany - mas que tiveram seu primeiro contato com a dança na experiência empírica, observando o Orixá em terra e os iniciados no Candomblé há mais tempo.

Percebemos o Afoxé como um espaço democrático que visa valorizar o conhecimento do indivíduo, tanto no segmento da dança quanto na percussão, pela compreensão da ideia de comunidade que se vivencia num terreiro de Candomblé, por mais que o grupo não conte apenas com iniciados na religião, mas a organização e o perfil das coordenadoras o leva a isso. 


\section{Referências}

ALVES, Teodora de Araújo. Herdanças de corpos brincantes: os saberes da corporeidade em danças afro-brasileiras. Natal: EDUFRN - 2006.

BARBA, Eugenio, SAVARESE, Nicola. A Arte Secreta do Ator - Um dicionário de Antropologia Teatral. São Paulo: É Realizações - 2012.

BOURDIEU, Pierre. O poder simbólico. 4. Ed. Rio de Janeiro: Bertrand Brasil - 2001.

CSORDAS, Thomas J. Corpo/Significado/Cura. Porto Alegre: UFRGS Editora - 2008.

FALCÃO, Inaicyra. Corpo e Ancestralidade - Uma proposta pluricultural de dança-arte-educação. Salvador: EDUFBA - 2002.

LIGIÉRO, Zeca. Corpo a Corpo - Estudos das Performances Brasileiras. Garamond. Rio de Janeiro - 2011.

LODY, Raul, SABINO, Jorge. Danças de Matriz Africana - Antropologia do Movimento. Rio de Janeiro: Palas, 2011.

MERLEAU-PONTY, Maurice. Fenomenologia da Percepção. São Paulo: Martins Fontes $-1999$.

MARTINS, Suzana. A Dança de Yemanjá Ogunté Sob a Perspectiva Estética do Corpo. Salvador: EGBA, 2008.

MORENO, Nany. Entrevista I [Jul. 2014]. Entrevistador: Daniela Beny Polito Moraes. Maceió, 2014. 1 arquivo .mp3 (85 min.)

NÓBREGA, Nadir. Dança afro - Sincretismo de Movimentos. Salvador: Editora Santa Maria: 1992.

Entrevista I. [Mar. 2014]. Entrevistador: Daniela Beny Polito Moraes. Maceió, 2014. 1 arquivo .mp3 (60 min.)

SCHECHNER, Richard. (Org. de Zeca Ligiéro). Performance e Antropologia de Richard Schechner. Rio de Janeiro: Mauad X Editora, 2013.

SEGATO, Rita Laura. Santos e Daimones. Brasília: Editora UnB, 2005.

VERGER, Pierre Fatumbi. Orixás. Salvador: Corrupio Edições, 2002. 
ZENICOLA, Denise Mancebo, Performance e Ritual - A dança das labás no Xirê. Rio de Janeiro: Mauad X Editora, 2014.

Recebido em: 24/04/2015

Aprovado em: 02/07/2015 